\title{
Development of multilayer coating system based on electrophoretic deposition process
}

\author{
Shota AZUMA, Hideto YAMADA*, Go KAWAMURA*, Hiroyuki MUTO**, \\ Takanori MIZUSHIMA and Atsunori MATSUDA ${ }^{* \dagger}$ \\ Department of Environmental and Life Sciences, Toyohashi University of Technology, Toyohashi, Aichi 441-8580, Japan \\ * Department of Electrical and Electronic Information Engineering, Toyohashi University of Technology, \\ Toyohashi, Aichi 441-8580, Japan \\ ** Institute of Liberal Arts and Science, Toyohashi University of Technology, Toyohashi, Aichi 441-8580, Japan
}

\begin{abstract}
The automatic multilayer coating system based on electrophoretic deposition process, including coating, drying, and washing, is proposed for stable preparation of multilayered films. As demonstration of the system, multilayered films consisting of layers of $\mathrm{LiNi}_{1 / 3} \mathrm{Mn}_{1 / 3} \mathrm{Co}_{1 / 3} \mathrm{O}_{2}$ (NMC) and $\mathrm{Al}_{2} \mathrm{O}_{3}$ particles were fabricated under constant applied voltage and current modes. The smoothly coated films were formed without any cracks or defects in both modes. The films with uniform thickness of each layer (average thickness of $\mathrm{NMC}$ and $\mathrm{Al}_{2} \mathrm{O}_{3}$ are 3.2 and $6.5 \mu \mathrm{m}$ respectively) were obtained at low constant current density. Results indicate that ordered film structure such as thickness of inside layers and layers number are controllable by simply varying the process flow conditions. It is expected that the system is able to be employed to make not only multilayered films but also particlereinforced composite materials.
\end{abstract}

(C2017 The Ceramic Society of Japan. All rights reserved.

Key-words : Electrophoretic deposition, Automatic processing, Multilayer structure, Ordered microstructure

[Received November 14, 2016; Accepted January 29, 2017]

\section{Introduction}

Ceramic materials have been increasingly used in a broad range of industries including biotechnology, pharmaceutical, dairy, food, and beverage, chemical and petrochemical, microelectronics, metal finishing, and power sources. In the latter, ceramics have been employed in solid oxide fuel cells, ${ }^{1)}$ solid oxide electrolysis cells, ${ }^{2)}$ secondary batteries such as lithium ion batteries, ${ }^{3)}$ thermo-electronic devices ${ }^{4}$ and solar cells. ${ }^{5}$ ) Recently, films with realizable complex structures are highly desired to have diverse multifunctions. For instance, homogeneous or multi-stratified films with controllable density of deposited particles, porosity and composite with different materials are all promising studies.

The fabrication of multilayered ceramics is a significant technique in the producing energy devices like capacitors, ${ }^{6}{ }^{6}$ thermoelectric devices ${ }^{7)}$ and tandem type dye-sensitized solar cells. ${ }^{8)}$ The development and commercialization of multilayer ceramic capacitors have been significant factors leading to size reduction of a variety of electrical circuits due to the micron-scale spacing of interleaved electrodes and high dielectric ceramics in multilayer ceramic capacitors provides exceptionally high capacitance in small volumes. ${ }^{6}$ Multilayered ceramics are often obtained by tape casting ${ }^{9-11)}$ and screen printing ${ }^{11), 12)}$ due to their simplicity and quickness. However, conventional methods have drawbacks as follows:

(1) Inability to obtain large area device with uniform quality.

(2) Difficult to obtain thicker film and thickness control.

(3) Coated substrates are limited to planar surface.

(4) Microstructure in casted films is uncontrollable.

\footnotetext{
Corresponding author: A. Matsuda; E-mail: matsuda@ee.tut.ac.jp
} * Preface for this article: Dol http://doi.org/10.2109/jcersj2.125.P4-1
Electrophoretic deposition (EPD) is an important technique for colloidal coating, ${ }^{13), 14)}$ which has the advantages of rapid, largearea deposition of films with high packing density and controllable thickness at a low-cost. It uses applied electric fields, to move electrically charged colloids or particles in suspension towards electrodes and finally to form films deposition it; the electrode shape is flexible depending on the practical applications. Normally, the multilayered films preparation by EPD are just at laboratory scale; complicated procedures including inserting/remaing electrode substrates into/from EPD bath suspensions, electric field applying, drying, and washing are manually controlled. Therefore, the multilayered films (consisted with relatively thinner layers, ex. $1-10 \mu \mathrm{m}$ ) obtained from manual process are nearly unrepeatable because of wide range of the procedures.

Therefore, the automatic multilayer coating system based on electrophoretic deposition process is proposed in this study. By introducing this system, rapid progress in functional films preparation with highly ordered architecture is expected.

\section{Experimental procedure}

\subsection{Concept of the EPD system}

Figure 1 shows the photograph of the main unit of the automatic EPD system and the block diagram of the EPD system is depicted in Fig. 2. In the automatic mode, three following functions can be programmed in any sequences (Fig. 3).

(1) Coating: in this function, EPD process can be operated under variable conditions. For instance, the deposition time, working mode (at constant voltage or constant current) and the wave shape can be all controlled.

(2) Drying: during this process, the hanging specimens are blown with heated air. Tunable airflow and heater are applied to control the flow rate and temperature. 


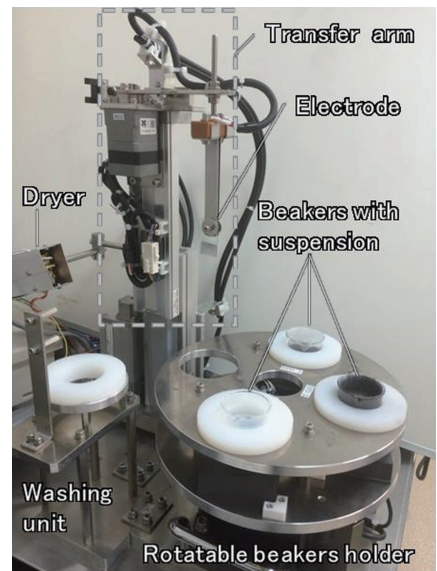

Fig. 1. Photograph of main unit of the EPD system.

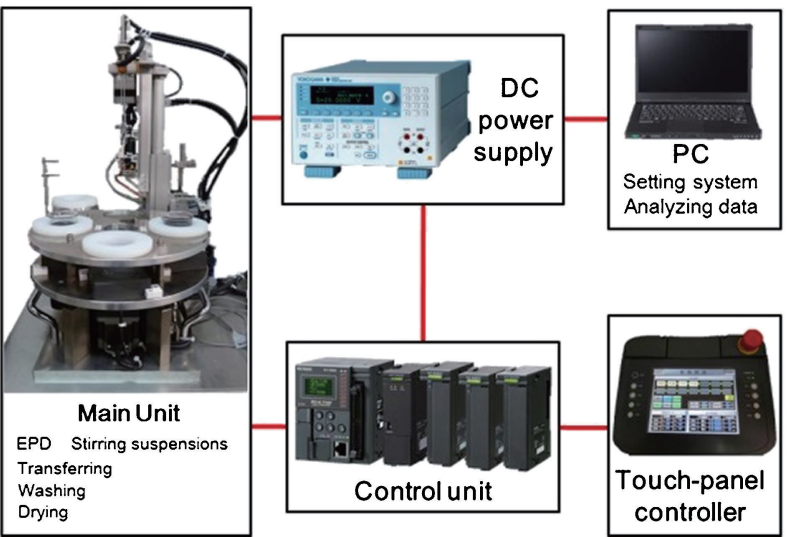

Fig. 2. Block diagram of overall EPD system.

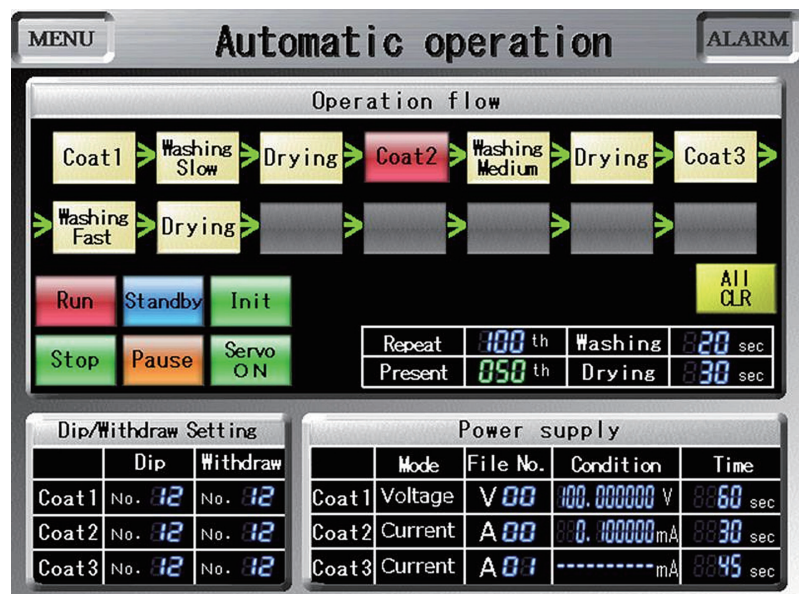

Fig. 3. Screen image of automatic operation mode in touch-panel controller.

(3) Washing: Specimens can be repeatedly dipped into solvent and then withdrawn until they are well-cleaned. Any solvent can be injected in and drained out automatically by a digital controlled pump.

The program allows no more than 14 processes in one working period. It can be repeated for at most 999 times.

\subsubsection{System configuration and detail of units}

This includes a touch-panel used as the control center, the EPD system is assembled by the following units:

\subsubsection{Control unit}

With power supply units and a programmable logic controller inside, control unit coordinate every part to work according to the scheduled program.

\subsubsection{Power supply unit}

DC power supply (Yokogawa Electric Co.) is used to apply not only constant voltage/current but also any editable wave shape during EPD process. The operation time is controlled by the touchpanel. Specifications of the power supply are shown as follows:

(1) Output:

- Voltage: $0- \pm 110 \mathrm{~V}$

- Current: $0- \pm 3.2 \mathrm{~A}$

(2) Resolution: $100 \mu \mathrm{sec}$

(4) Instantaneous voltage/current information can be saved for further analysis during appication.

\subsubsection{Transfer arm with electrode}

Handing the specimens, the transfer arm can move it to 3 locations for different processes. It also has a function to immerse the specimens into the beakers during the EPD for washing process. All the movements are digitally controlled by the touch-panel.

Additionally, an electrode which can connect the substrate to the DC power supply is also assembled on the transfer arm.

\subsubsection{Rotatable beakers holder}

Depending on the processes, by self-rotation, the holder can place the specific beaker underneath the electrode transfer arm. In the rotator, there are three locations for different kinds of suspensions. Below each beaker, a speed adjustable stirrer is set to give continues/discontinue mixing for the whole EPD process.

\subsubsection{Washing unit}

With this unit, after EPD process, specimens are repeatedly dipped into washing solvents to remove extra particles which are loosely attached on the substrates. Based on specific cases, the dipping times, and the frequency can also be adjusted by touchpanel.

\subsubsection{Dryer}

Washed specimens are dried by the dryer. The temperature, air flow and heating time are controlled by touch-panel.

\subsubsection{Data analyzer}

In order to receive and analyze the voltage/current data during EPD process, a PC was connected to the power supply unit.

\subsection{Multilayers preparation procedure \\ 2.2.1 Preparation of suspensions}

The surface of $\mathrm{LiNi}_{1 / 3} \mathrm{Mn}_{1 / 3} \mathrm{Co}_{1 / 3} \mathrm{O}_{2}(\mathrm{NMC}, 1 \mu \mathrm{m})$ and $\mathrm{Al}_{2} \mathrm{O}_{3}$ $(100 \mathrm{~nm})$ particles were coated with poly(diallyldimethylammonium chloride) (PDDA, $M_{\mathrm{w}}: 400,000-500,000$, Ardrich $^{\odot}$ ) by mixing PDDA aqueous solution $(10 \mathrm{wt} . \%)$ followed by ultrasonication for $30 \mathrm{~min}$. The modified particles were dispersed into 2-propanol by ultra-sonication for another $30 \mathrm{mins}$. As a result, the as obtained suspensions of $\mathrm{NMC}$ and $\mathrm{Al}_{2} \mathrm{O}_{3}$ with $3 \mathrm{wt} . \%$ concentration were then used for the following coating procedures.

\subsubsection{Alternately deposited multilayered films}

EPD was carried out by using indium tin oxide (ITO) coated glass substrate $(20 \times 30 \times 0.7 \mathrm{~mm})$ as the anode while on the parallel cathode, similar ITO coated glass substrate was used at a distance of $0.5 \mathrm{~cm}$. During EPD process either constant voltage of $50 \mathrm{~V}$ or constant current density of $10 \mu \mathrm{A} \mathrm{cm}^{-2}$ the was applied for $60 \mathrm{~s}$. In order to obtain the multilayered films, the following cycle was repeated for 5 times:

(1) Coating of $\mathrm{Al}_{2} \mathrm{O}_{3}$

(2) Washing

(3) Drying

(4) Coating of NMC 
(5) Washing

(6) Drying

\section{Results and discussion}

The multilayered films obtained consist of altarnate EPD by applying $50 \mathrm{~V}$ are shown in Fig. 4, in which no crack or defect could be observed owing to the precise controlled process. as it is difficult to obtain this quality manually. Figures 5 and $\mathbf{6}$ illustrate cross-sectional images of the films with $\left(\mathrm{Al}_{2} \mathrm{O}_{3} \mid \mathrm{NMC}\right)_{5}$ on ITO glass deposited by applying constant voltage and current density, respectively. As shown in these images, multilayered structure formed by NMC (black layers) and $\mathrm{Al}_{2} \mathrm{O}_{3}$ (white layers) can be clearly observed. The total thicknesses of the multilayers are 250

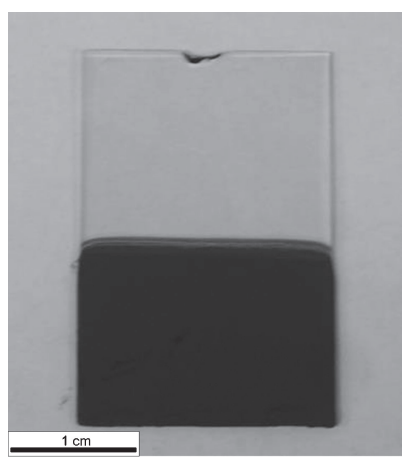

Fig. 4. Photograph of multilayered films with $\left(\mathrm{Al}_{2} \mathrm{O}_{3} \mid \mathrm{NMC}\right)_{5}$ structure on ITO glass prepared under constant voltage of $50 \mathrm{~V}$.

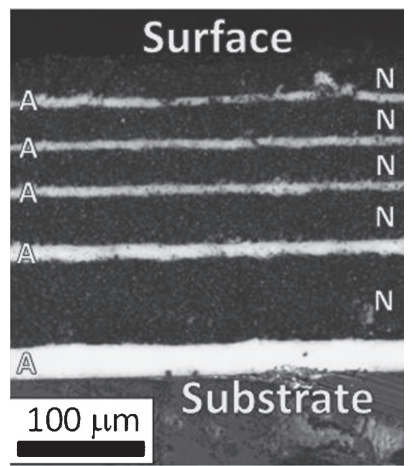

Fig. 5. Cross-sectional image of multilayered films with $\left(\mathrm{Al}_{2} \mathrm{O}_{3} \mid \mathrm{NMC}\right)_{5}$ structure on ITO glass fabricated by applied constant voltage of $50 \mathrm{~V}$; where $\mathrm{A}$ denoted on white layers is $\mathrm{Al}_{2} \mathrm{O}_{3}$ layer; $\mathrm{N}$ denoted on black layers is NMC layer.

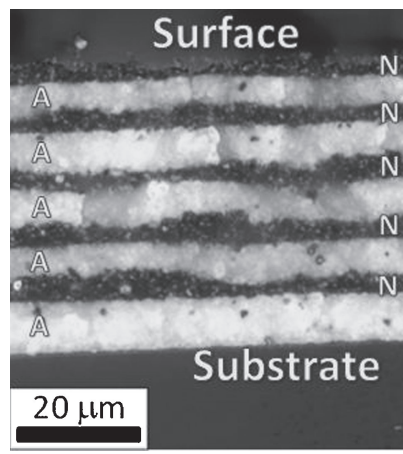

Fig. 6. Cross-sectional image of multilayered films with $\left(\mathrm{Al}_{2} \mathrm{O}_{3} \mid \mathrm{NMC}\right)_{5}$ structure on ITO glass fabricated by applied constant current density of $10 \mu \mathrm{A} \mathrm{cm}^{-2}$; where $\mathrm{A}$ denoted on white layers is $\mathrm{Al}_{2} \mathrm{O}_{3}$ layer; $\mathrm{N}$ on black layers is NMC layer. and $46 \mu \mathrm{m}$ for Figs. 5 and 6, respectively. The thickness of each layer in the films was controlled by adjusting EPD conditions such as applied voltage, current density, and time. By repeating each coating process, more layers in the films can be achieved. The correlations of each layer thickness and layer number obtained from Figs. 5 and 6 are shown in Fig. 7. Even when EPD voltage was kept the same, each film became thinner gradually: thickness of $\mathrm{NMC}$ layers and $\mathrm{Al}_{2} \mathrm{O}_{3}$ layers decreased from 70 to $30 \mu \mathrm{m}$ and from 30 to $5 \mu \mathrm{m}$, respectively. The thicker the total films are, the thinner the new coated layer became due to the lower deposition rate. In contrast with the constant voltage mode, employing constant current density mode, more consistent regular thickness was apparently formed, which showed average thicknesses of 3.2 and $6.5 \mu \mathrm{m}$ for $\mathrm{NMC}$ and $\mathrm{Al}_{2} \mathrm{O}_{3}$, respectively. Films with homogeneous multilayered structure are crucial in their application. Therefore, it was considered that constant current mode was more suitable for the preparation of uniform multilayered films.

The reason of reduced films thicknesses under applied constant voltage mode is probably due to the resistance increment during films formation. As for constant voltage EPD deposition, increasing resistance in each deposition layer against EPD time and numbers of layers are confirmed in both $\mathrm{Al}_{2} \mathrm{O}_{3}$ and $\mathrm{NMC}$ [Figs. 8(a) and 8(b)], In other words, newly deposited films on top of the under-layers become thinner under constant applied voltage due to the increased resistivity of the under-layers. Additionally, transition trends of resistance are influenced by various factors such as surface/internal structure of under-layer, particle size, etc. Hence, the precise thickness control of each layer is difficult in the constant voltage mode.

Then, Figs. 9(a) and 9(b) explain the voltage transition for EPD of $\mathrm{Al}_{2} \mathrm{O}_{3}$ and NMC respectively under applying constant current. In corresponding with increased resistance as indicated in Fig. 8, the voltage curves exhibit rising trend against EPD time and number of deposited layers. Thus, although higher resistance with increasing number of deposited layers, thickness of newly formed films on top of under-layer was maintained due to compensated voltage in employing constant current density mode.

Briefly, using this automatic EPD system, over 100 layers can be coated easily if deposition conditions are optimized. Theoretically, according to the specification of the system, at most 999 layers can be formed by simply repeating the program. Furthermore, it is also expected to produce particle-reinforced composite materials. Schematics of EPD procedure for fabricating this kind of material are illustrated in Fig. 10. For example, in the case to prepare a composite film containing two kinds of particles de-

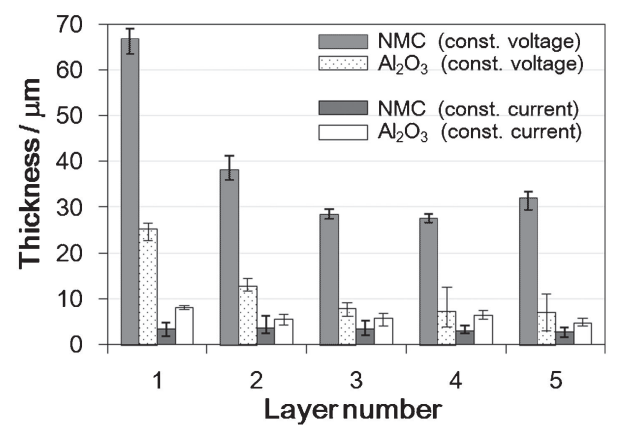

Fig. 7. Thickness of each layer in $\left(\mathrm{Al}_{2} \mathrm{O}_{3} \mid \mathrm{NMC}\right)_{5}$ films fabricated under applied constant voltage of $50 \mathrm{~V}$ and constant current density of 10 $\mu \mathrm{A} \mathrm{cm}^{-2}$; where error bars indicate obtained maximum and minimum thickness in each number of layer. 

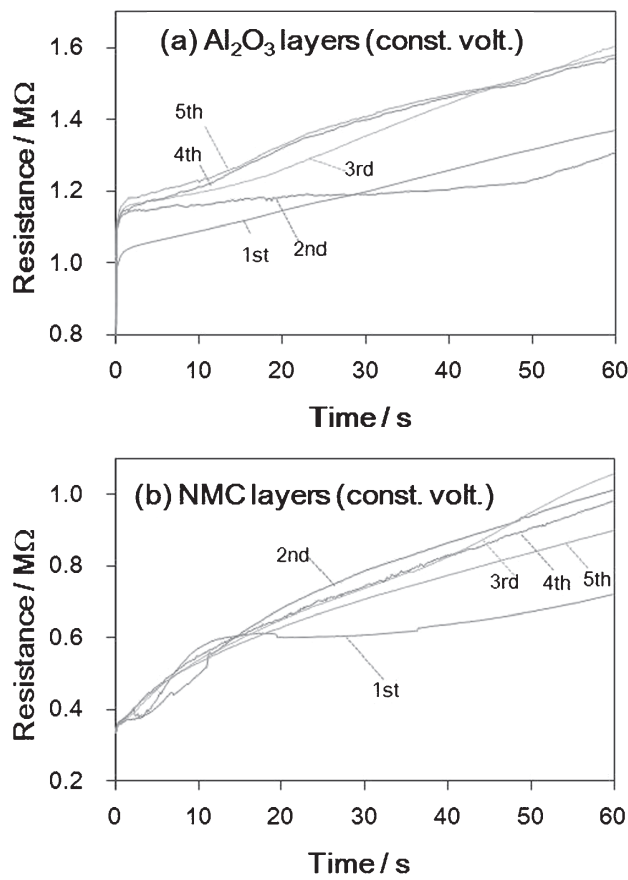

Fig. 8. Transitions of resistance density for each layer with (a) $\mathrm{Al}_{2} \mathrm{O}_{3}$ and (b) NMC under applying constant voltage.
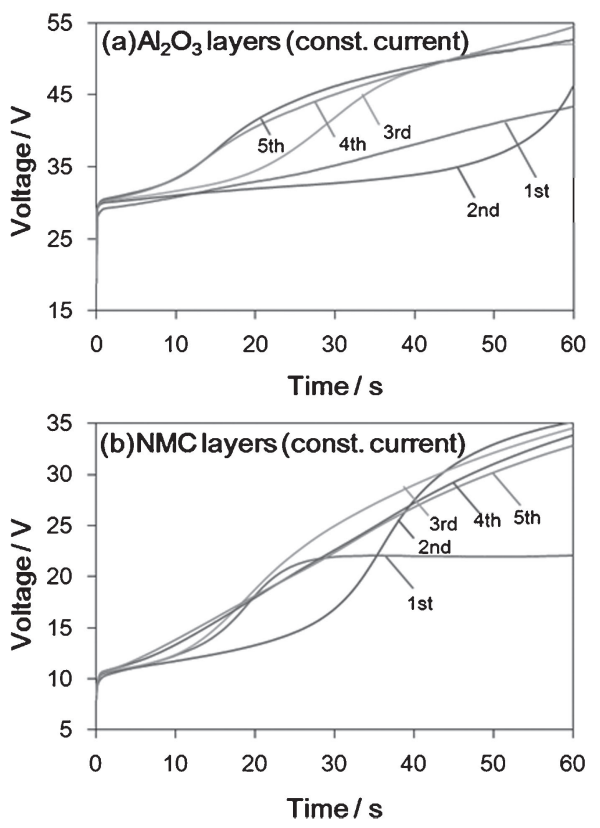

Fig. 9. Transitions of voltage for each layer with (a) $\mathrm{Al}_{2} \mathrm{O}_{3}$ and (b) NMC under applying constant current.
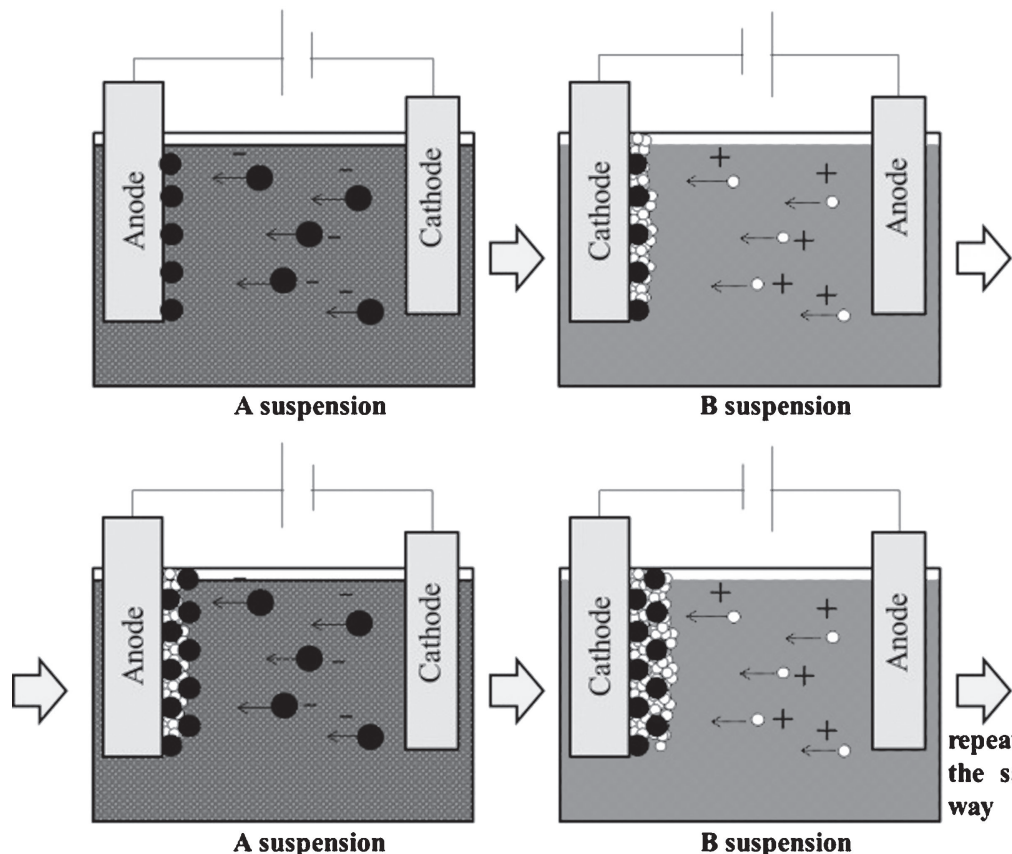

B suspension

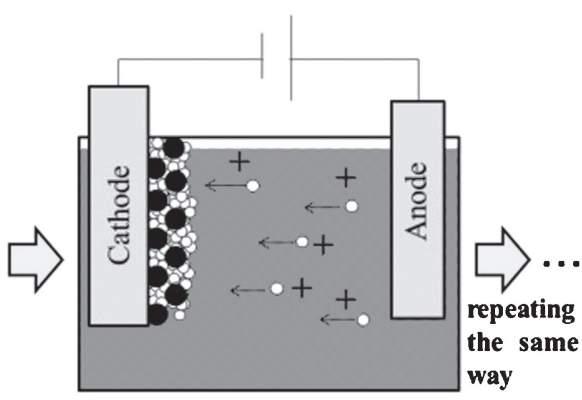

B suspension

Fig. 10. Scheme of fabrication procedure for particle-reinforced composite films using EPD

scribed as A and B, in suspension, A particles are first deposited on the electrode to form a sub-monolayer. Then, followed by replacing the specimen from A suspension into B suspension, B particles are deposited on to the so-coated films. Particularly, they would fill the space between A particles. By repeating the processes above, particle-reinforced composite films could be obtained using the automated EPD system. The composite films would be served as electrode in energy devices. In our future study, the automated EPD system will be employed for the preparation of composited cathode layer in solid-state lithium ion batteries based on sulfide electrolyte.

\section{Conclusions}

In this study, the automated EPD system that includes coating, drying, and washing processes, was proposed for a fabrication of multilayered films. As a result, smooth multilayered films without any defects were prepared using this system. The specific microstructures such as the thickness of each layer and their total number were controllable by adjusting detail conditions. The performance of the system has been proven to be qualified for multilayered films preparation. Moreover, we proposed utilizing this system to fabricate particle-reinforced composite films. 
Acknowledgement We acknowledged Shinko Denso Co. Ltd's. help in developing the EPD system. Financial support for this work was provided by the Advanced Low Carbon Technology Research and Development Program, Specially Promoted Research for Innovative Next Generation Batteries (ALCA-SPRING) from Japan Science and Technology Agency (JST).

\section{References}

1) N. Q. Minh, J. Am. Ceram. Soc., 76, 563-588 (1993).

2) M. Ni, M. K. H. Leung and D. Y. C. Leung, Int. J. Hydrogen Energy, 33, 2337-2354 (2008).

3) J. W. Fergus, J. Power Sources, 195, 4554-4569 (2010).

4) S. B. Riffat and X. Ma, Appl. Therm. Eng., 23, 913-935 (2003).

5) R. Jose, V. Thavasi and S. Ramakrishna, J. Am. Ceram. Soc., 92, 289-301 (2009).
6) H. Kishi, Y. Mizuno and H. Chazono, Jpn. J. Appl. Phys., 42, 1-5 (2003).

7) G. D. Mahan and L. M. Woods, Phys. Rev. Lett., 80, 40164019 (1998).

8) A. Mishra, M. K. R. Fischer and P. Bäuerle, Angew. Chem., Int. Ed., 48, 2474-2499 (2009).

9) C. Pithan, D. Hennings and R. Waser, Int. J. Appl. Ceram. Technol., 2, 1-14 (2005).

10) H. Liu and S. M. Hsu, J. Am. Ceram. Soc., 79, 2452-2457 (1996).

11) D. I. Woodward, I. M. Reaney, G. Y. Yang, E. C. Dickey and C. A. Randall, Appl. Phys. Lett., 84, 4650-4652 (2004).

12) C. Pithan, D. Hennings and R. Waser, Int. J. Appl. Ceram. Technol., 2, 1-14 (2005).

13) L. Besra and M. Liu, Prog. Mater. Sci., 52, 1-61 (2007).

14) T. Uchikochi, Micromeritics, 57, 36-42 (2014). 